\title{
Globalization and Scapes: A New Theory of Global Dynamics
}

\author{
Jason L. Powell ${ }^{*}$ \\ Department of Social and Political Science, University of Chester, CH1 4BJ, United Kin \\ *E-mail address: Jasonpwll3@gmail.com
}

\begin{abstract} cultural, technological, political and economic change.
\end{abstract}

Globalization has produced a distinctive stage in the social histor of with a growing tension between nation state-based solutions and an etres an ose fo mulated by global institutions (Powell, 2011). Globalization, defined here as th cess where ation-states are influenced (and sometimes undermined) by trans-national actor (Hun identity has, itself, become relocated within a trans-national context, with international or isations as the World Bank and International Monetary Fund) and cross-border migrations creating new con cons and environments for many displaced people (Estes, Biggs, \& Phillipso 2003). This paper examines the work of Appadurai and the extent to which has had a large imp on underst nding the global dynamics of

Keywords: Globalization; Scapes; Power; Nation

\section{INTRODUCTION}
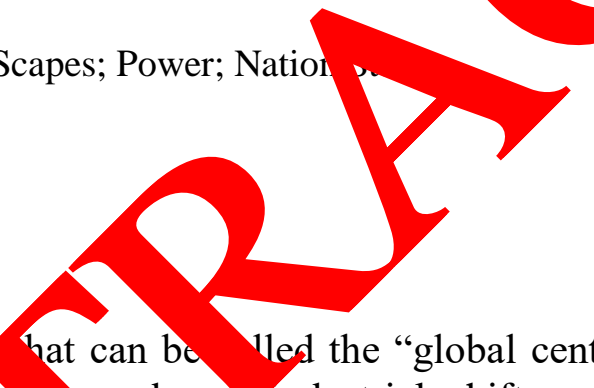

As we move into "hat can bo led the "global century", many aspects of social and economic life are ang and pos -ndustrial shifts are unparalleled by virtue of the interconnectednes thut bring ogether the far corners of the globe. New technologies, new economic rela onships, new cial processes, and new political developments are all characteristi of glo lization in a postindustrial age featured by information, innovation, finance, and s ces. As he world has contracted, people's quality of life has changed regard f who they live. In fact, the propagation of free market mindsets in emerging eco omies as creat collective network connections with considerable good but pervasive ineq itie a key aim of this paper is to explicate how these changes are of grand scale, they are part of what globalization is all about, and how they play out in terms of risks and alities shaping human experience linked to the work of Appadurai. There is a tension with this. On the one hand, life expectancy, health statuses and per capital incomes are at an all-time high and many feudal practices have been relegated to the past (Phillipson, 2006). On the other hand, vast numbers of people struggle with poverty and significant pockets of poverty portend more than lack of income. Around the globe there are bona fide challenges facing nation-states as they attempt to adapt to the impact of modifications in morbidity, mortality, and need gradients among diverse segments of their populations. In the face of rapid demographic transformations resulting in fewer casualties from acute diseases, aging of populations, and tumultuous economies, there are widening disparities between the 
"rich" and the "poor" and considerable quality-of-life inequalities within and between populations. In developing countries, China being one of the most striking cases in point but with parallels in a number of other developing countries the differential in per capital incomes of urban and rural people is at least a factor of three with virtually no top quartile wage earners residing in rural areas (Powell, 2011). Not surprisingly, there is a tangible rural to urban migration for economic gain, thereby creating even greater disparities as those left behind barely eke out subsistence livings.

Demographers have forecast dramatic increases in cultural diversity in the general population of the globe, which will also be reflected in increasing populations. Globolization has also produced a distinctive stage in the social history of populational projec ions, a growing tension between nation state-based solutions and anxieties and those rmulated global institutions (Powell, 2011). Globalization, defined here as the proces wh by natio states are influenced (and sometimes undermined) by trans-national ac.ors. Huma den ty has, itself, become relocated within a trans-national context, with in nation organ ctions (such as the World Bank and International Monetary Fund) an cr order in grations, creating new conditions and environments for many displace people sial men and women (Estes, Biggs, \& Phillipson, 2003). It should also be st ed that at sity does not appear to strike women and men equally - and it is ertain reasonable to say that disadvantage begets disadvantage when downturns ceu Wome. $\%$ disproportionately among the most disadvantaged and with age even gr ter hardships acc ue to them. Adding to the intricacies of these unparalleled changes is the locity with which they are taking place and the fact that they are accompanied by a deepenin livision be tween those whose principal pursuits are in subsistence or service sectom-markets a involved in large-scale export, international or equity markets. Together these forces are bringing about a profound imbalance with $\mathrm{n}$ a an een populations as one group shares in the generation of wealth while the other comes increasingly dependent and is being subordinated to decisions made in th other s tor, by a cartel half a world away. Indeed, these risks are not grounded $b \quad \mathrm{ly}$ in the absen.e of resources but in an absence of personal

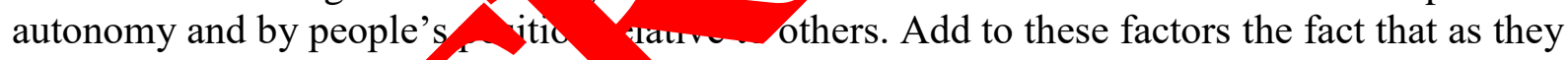
wrestle with the issues ational a local governments are assailed from multiple fronts; pressed by transnatic al rests to $\mathrm{p}$ ovide open trade liberalization for private enterprise; and pressed by thewing for social protections and labor policies to sustain the working popul ce and those w thes have fallen through the proverbial social safety net. Ever more lusive rotections call for targeted expenditures at exactly the time when expenditures a mmed- by capacity to levy taxes of any type but especially progressive taxes by $p$ rful interested constituencies. The neoliberal globalizing drive has dise franc sed wor $s$ and their representatives in ways that have eroded their ability to bary fo lonofits. Many commentators have noted that governments have generally adopte laisse 2 faire stance when for one reason or another they have chosen not to intervene be disempowerment of the citizenry.

The york of Appadurai has had a large impact on understanding the global dynamics of cultural, technological, political and economic change.

\section{THE POWER OF GLOBAL SCAPES}

For Appadurai (1990), the global situation is interactive rather than singly dominated. The United States no longer dominates the world system of images, but is only one node of a 
complex transnational construction of "imaginary landscapes." In his widely cited paper "Disjuncture and difference in the global cultural economy," Appadurai argues that in this new conjuncture the invention of tradition and other identity-markers becomes slippery, as the "search for certainties is regularly frustrated by the fluidities of transitional communication" (Appadurai, 1990, p. 5) He also stresses that there are various fears besides that of Americanization: "it is worth noticing that for the people of Irian Jaya, Indonesianization may be more worrisome than Americanization, as Japanization may be for Koreans, Indianization for Sri Lankans, Vietnamization for Cambodians, Russianization for the people of Soviet Armenia and the Baltic republics," and we must acknowledge that "one man's imorined community is another man's political prison." (Appadurai, 1990, p. 6).

Appadurai posits the imagination as "central to all forms of agency, [ar tself a soo fact, and [as] the key component of the new global order. To understard, w ust bri together an understanding of the Frankfurt school idea of images; Anderson's agi ed community, and the French idea of the imaginary (imaginaire). Appar rai pro to a new vocabulary that helps us to understand the "new global c tur onomy" itself a product of "disorganized capitalism" and a complex of "fund nental a nctur os between economy, culture, and politics" (Appadurai, 1990, p. 328). To Yerstand th disjunctures, he posits an interrelating framework of "global cultural ws" vadurai (1990, p. 328), termed -scapes because of their fluidity, their depende an perspe (a landscape looks different depending on how you look and who is lo king): Ethnoscap es - the ever shifting "landscape of persons who constitute the shift g world in which we live: tourists, immigrants, refugees, exiles, guestworkers, and ther mo ing groups and persons" (Appadurai, 1990, p. 329). Mediascapes- "refer the distribution of electronic capabilities to produce and disseminate towion (newspapers, magazines, television stations and film production studios) which a ne rable to a growing number of private and public interests throughout the world, an to the images of the world created by these media" (p. 330). "Tend to be nag ntered, arrative-based accounts of strips of reality (Appadurai, 1990, p. 331)". shno capes - the global configuration, also ever fluid, of technology, and of the f the ecmunoy, both high and low, both mechanical and informational, now mo s at high eds across various kinds of previously impervious boundaries" driven $b$ "h asingly mplex relationships between money flows, political possibilities, and he nvaila $v$ of both un- and highly skilled labor (Appadurai, 1990, p. 329-330)". Fir anscapes - the w of capital: "currency markets, national stock exchanges, and commo $\mathrm{Y}$ spe ations move mega-monies through national turnstiles at blinding speed" (Appac 1990, 330). Ideoscapes - "Also concatenations of images, but they are often di ly poh an frequently have to do with the ideologies of states and the counteride ogies f move unts explicitly oriented to capturing state power or a piece of it" (Ap ur 1000 . 331). For Appadurai, building on Anderson, these -scapes "are the buildìn Tocks or...imagined worlds, that is, the multiple worlds which are constituted by the historical taated imaginations of persons and groups spread around the globe" (Appadurai, 1990, p. 329). These intertwining and fluid landscapes help us to see the dynamic between homogenization and heterogenization at play every in these disjunctures between these global flows. To mark this, Appadurai first splits Marx's classic fetishism idea into two: 1. production fetishism- "illusion created by contemporary transnational production loci, which masks translocal capital, transnational earning-flows, global mangagement and often faraway workers...in the idiom and spectacle of local (sometimes even worker) control, national productivity and territorial sovereignty" (Appadurai, 1990, p. 333). 2. fetishism of the consumer - consumer turned into a "sign" where the control of producers masks itself via 
advertising in assertions of consumer agency (Appadurai, 1990, p. 333). This is a global homogenization which is "repatriated as heterogeneous dialogues of national sovereignty, free enterprise and fundamentalism in which the state plays an increasingly delicate role....as arbitrater of this repatriation of difference." (Appadurai, 1990, pp. 333-334). The problem of "reproduction in the age of mechanical art:" enculturation even at family level in age of deterritorialization and instability hastened and made more acute by mechanical arts in media and ideoscapes. Example of gender and violence is getting more and more difficult and torn (Appadurai, 1990, p. 335-336). Appadurai (1995a) stresses that globalizing and localizing processes, or "global homogenization" and "heterogenization" feed and reinforce each-other rather than being mutually exclusive, and he calls for more anthropological stares on "production of locality". These sociological changes are also reflected in ty exchange ideas and values as well as imagination. As the movement of people influences es as w as countries, even people who are not mobile themselves come in con act with ideas, practices, technology, information and economic practices flows thou go ween people. A good way of modelling the complex interchange of thou ts een ped is as a cultural economy (Appadurai, 1996).

\section{CULTURE AND SCAPES}

The different dimensions of the cultural econd y may be a d often are disjoint. People in one place may feel one way about economics and other way, incompatible with the first, about immigration. These disjunctures pav even of a single individual. The disjunctures in the global cultural econom explored by looking at the relationship among five dimensions of global flows: The uff e indicates fluidity and irregularity, because it is a matter of fact that thevare all in onstant change. As people move, ethnoscapes change; as technology is moved arou and in nted, technoscapes change; as capital moves around the world as part of th bal conomy, inancescapes change. Extension and changes in reach of media from di en ces mediascapes change. Different television and radio channels are avg ble in di ent places. When ideas are exchanged and spread, ideoscapes change $\mathrm{pp}$ rai, 1996 Global scapes occur in and through the growing disjunctures amop hese lâ capes. These landscapes are the building blocks of multiple imagined world of historically dated imaginations of persons and groups around the world. As people er unter flows, they do so within their historical context. From their context and the flows, 4 const ct a worldview. The scapes are deeply perspectival constructs. Theref he wo viey that anyone of us constructs depends on who we are, where we are, and what apes we and how we interpret them; therefore there will be multiple ways of inta ing 4orld, and so there will be multiple imagined worlds (Appadurai, 1996). Appad sees modernity as the practice of imagining where you would like to be. Following Emile Du $\%$ m, anthropologists view collective representations as objective social realities and facts (bwell, 2005). Appadurai proposes that due to relatively recent changes founded on technological changes, imagination has become such social fact, and that this leads to a "plurality of imagined worlds." (Appadurai, 1996) He argues that imagination has become part of everyday, ordinary life for ordinary people, instead of being the sole domain of the privileged and powerful. Ordinary people can and do imagine themselves in different circumstances and different places, due to the increased rates of migration and the technologies that transmit images of other lifestyles and other places. He emphasizes that these lifestyles and places are not fantasy, but are more properly imagined than fantasized. 
The mediascapes that people are exposed to stimulate agency and the imagination fuels action rather than dreams of escape. This imagination is taking place on an individual scale, but the collective imagination of a group of people that begin to feel and imagine things together is pivotal. As groups share collective imagination, they create new social realities. (Appadurai, 1996).

\section{PROBLEMATIZING FINANANCESCAPES AND CULTURE}

The term 'financescape' is one of the perils of economic globalization, defint s "cross-border movements" of loans, equities, direct and indirect investments d currenc that transcend the power of the nation state. Appaduerai (2006) furth describ financescapes as the imperialism of global flows of finance in which w controlled ra $1 \mathrm{~d}$ movements of capital can destabilise national economies. It is the ey ving f ncesc $c$ and its uncertain future that is made visible through the contemporary o di s s that is apid due to changes in currency markets, national stock exchanges, and commod pecy ations and the speed at which they move at in the global arena (Es cs, iggs \& H ipson, 2003). Financescapes focus on the flow of currencies, securities a d of tal. To ake an example of organised crime and relationship to financescapes, Firamescapes a oytended through deregulation and have made it easier for vast sums of money to travel the globe and be laundered by criminal organisations without interfe nce from na ional governments. Mythen and Walklate (2006) makes the point that transnation organised crime syndicates are able to protect their financial resources in foreign hank accou. are able to network with other criminal organizations in diverse countri acquire the necessary funding for their activities. Financial payments for these dift rentso es as well as the necessary money laundering is facilitated by escapinomation sto s the availability of banking secrecy, lack of regulation and electronic financi at tra fers tha can move money within seconds on a global scale. In weak or failing sta suc rapid movements of capital are enough to provoke economic and political co ose yulklate, 2006). Financescapes are also the product of another glo dynamio rivatization and the decline of the nation-state. Sere difficulties are inher nt he capac, es of individual nation states to "fix" or "correct" problems that mare cult fro the pressures of financial markets with few controls and little social regulatig (Marginson d awir, 2005). When things go wrong, costly bailouts by the state can be pecter or finaneial speculators. Appardurai (1996) observes that the logic of this financial mony to decrease government expenditures and state intervention through yatizà and contracting out and do away with capital contributions. Following this App arai (2y, has characterised the international financial sector to a 'casino' ne. or wich assets are traded increasingly by non-bank, private financial institutions, entires r speculative profit. The emergence of 'around-the-world' 24/7 financial markets, where ma tossborder financial transactions are made in cyberspace represents a familiar example o the economic face of globalization (Estes, Biggs, \& Phillipson, 2003). The definition and social construction of 'the problem' of state power is transferring from the state and its citizenry to private sector global finance (Appadurai 1996; 2006; Estes, Biggs \& Phillipson, 2003). For example, Powell (2006) points to how the economic stakes and social consequences of 'aging populations' cannot be underestimated for the upholding of power by multi-national corporations. Looking ahead, the race is on for 'Global Custody' through the socially constructed 'Ticking of the Pensions Time Bomb', as described by the Financial Times with Europe as a 'battleground' for the US Banks (The Bank of New York, State Street 
Bank, JP Morgan and Citibank) competing against the European Deutsche, BNP Paribas and HSBC for custody of the growing pensions market and the highly lucrative financial services supporting it. As further incentive to eager financial enterprises, the 'global picture' in private wealth drawn from the lucrative business of pension providing is by 2012 to exceed $\$ 13,000$ billion in the USA, \$10,000 billion in Europe, and \$7,200 billion in Asia (Powell, 2011). In other words, capital flow is being re-invented through pensions in financescapes. Financescapes simultaneously brings home - and exports - the processes of privatization, competition and rationalization as well as the transformation of pension sectors of society through flexibilization and deregulation (Estes, Biggs, \& Phillipson, 2003). Finanoncapes greatly extends the corporate capacity of capital to "exit" a nation (and there y to es corporate responsibility and/or taxation) in the course of struggles over regula of finand resources (Appadurai, 1996; 2006).

\section{EXAMPLES OF GLOBAL SCAPES: THE CASE OF THE TO UNIVERSITY \\ Appadurai (1996) examines 'globalization', wbic he erprets as 'worldwide} connectedness' through the idea of 'global scapes'. Tom ving Ap 'rai (1996), we can postulate five dimensions of such global scapes tha influence the wo $k$ of Universities (and academics) in the globalised environment: et oscapes, tchnoscapes, mediascapes, financescapes and ideascapes. Taken as an example the uniy rsity, it is these dimensions that characterise the construction of knowledge across nes. That is, people (academic researchers) travel to conferences, read tionally refereed publications, write for internationally published academic journa $3 \mathrm{oks} /$ monographs, use international perspectives and networks to inform their $\mathrm{rc}$ arch etc. The interconnectedness of people provides the ethnoscape of the acaa ic worl The global technology of the 'world wide web' facilitates the identificat of $\mathrm{k}$ owledge .ources, allows up-to-date access to the latest research, and provides glo con email, blogs and Web 2 data processing capacities. This is the hnoscape ithin which we live our academic lives. Mediascapes provide information a d r from a sund the world, scripts and scraps of narrative that are the resources that an be in rely reassembled and provide global relevance to prospective research projec $s$. The use of a ance learning by new modes of media such as web based learning par oes, yning portals, and on-line undergraduate and postgraduate degrees illustrate the du and bre lth of media information of education beyond the physical layout of the versity Maro nson and Sawir (2005) agree, noting that distance education is evo ing to a py Fordist global instructional corporatism of open education. The iceo ne the inages and big ideas about the potential of global interconnectedness that inform rintentons and underpin our 'realities'. "The ideoscape of the "global university" promised dom of a kind, positioning it as an autonomous institution providing passage to knowledge, resources and possibilities unimpeded by national government. The ideoscape of the 'global university' provides the possibility for research to be globally as well as locally relevant.

Financescapes flourish in an open trading environment in which the mode of interaction is as much competitive and cooperative; commercial infrastructures facilitate academic activity and, increasingly, high profile research. The fact that we recognise these dimensions of 'global flows' so easily as they are present in the modern university, should mean that a globalised research program in universities with a will to locate themselves internationally 
and globally. In the field of University education, however, the boundaries and barriers to international research obstruct the global flows. The boundaries which define and, to a greater or lesser extent, inhibit joint research efforts are not only the geographic boundaries of the geo-political world, they are also cultural, methodological and sociological (Danaher \& Wyer, 1995). The boundaries within which knowledge is constructed and across which knowledge construction might take place, but which might be obstructive of the global flows are: Nation State boundaries: (e.g.) UK, USA and Australia Geo-cultural boundaries: (e.g.) East/West Geo-economic boundaries: (e.g.) The North/South divide Epistemological and methodological boundaries: (e.g.) interpretive and participatory methodologies vs. pocitivistic research methodologies. Marginson and Sawir's (2005) and Appadurai's (206) g 1 flows' are, indeed, obstructed by some of the same 'scapes' that characterise $f$ "al acaden work. Ethnoscapes remind us that the academic 'flow' of University personnel vithin at towards those already sharing common academic traditions, concepts ar a languago Lat er, 2004). The technoscapes that facilitate and define the academic lan sape d not pr ide a uniform vista of instant and reliable access. In many of the mo sis ant res reh sites technology is not reliable, access not widely available (Margin on \& Sau 2005\%. Although the global university might be connected into the financesca es internatio research and commercial patents, international educational research does not $\mathrm{t}_{\mathrm{c}}$ in the financescape of the global university (Lather, 2004). Moreover, increas the resea that is most likely to be successful in attracting large-scale funding is th at which meets t, e 'Gold Standard' of ramdomized field trials (Lather, 2004), rather than p ticipatory, ctse-based research.

\section{CONCLUSION}

This paper has attempted to exnlore App durai's implicit conceptual toolkit to examine facets of culture. Quite audacio asty, e differ ntiates five dimensions of global "scapes," flowing across cultural bound s: 1) ethnoscapes, the landscape of persons who constitute the shifting world in wb the global configuration of technologies moving at sh speeds oss previously impermeable borders; 3 ) financescapes, the global grid of cur enc eculation nd capital transfer; 4) mediascapes, the distribution of the capabilities to roduce a disseminate information and the large complex repertoire of images and nar atives generate $y$ these capabilities; and 5) ideoscapes, ideologies of states and counter bolog of movements, around which nation-states have organized their political cultur

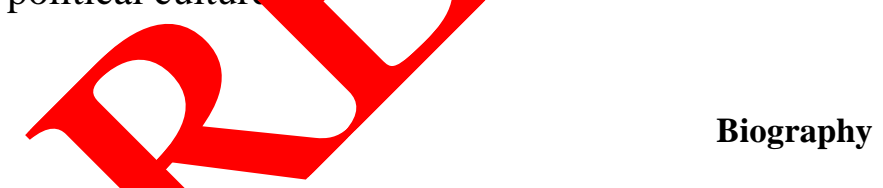

Hon Prot Jason L. Powell BA (Hons), MA, Ph.D, FRSA is University Lecturer, Honorary Professor and Adjunct Prol or. He is formerly Professor of Social Gerontology and Associate Dean of Faculty of Health and Life Sciences at University of Coventry. He holds an Honorary Fellowship at University of Liverpool; Honorary Professor at Australia-Asia Research and Education Foundation at Tasmania University; Visiting Research Fellow at Oxford; and recently invited as Visiting Scholar at Harvard University. He has been Visiting Professor in Canada, US, Australia, Africa and Jordan. He was nominated and elected to Fellowship of the British Royal Society of Arts (FRSA) in recognition of his research. He has strong interests in social theory, ageing, power and identity. He is author of Social Theory and Ageing (2006) which was part of Charles Lemerts distinguished „New Social Formations book series, Rowman and Littlefield: New York. 


\section{References}

[1] Appadurai, A. (1996). Modernity at Large Cultural Dimensions of Globalization, Minneapolis: University of Minnesota Press.

[2] Appadurai, A. (2006). The right to research, in Globalization, Societies and Education, $4(2), 167-177$.

[3] Danaher, P. A., \& Wyer, D. W. (1995). Itinerant education as border pedagogy: The globalization and localisation of show culture. In F. Nouwens, (ed.). (1995) Distance education: Crossing frontiers (pp.154-159). Papers for the 12th Biennial Fory 1 or th Open and Distance Learning Association of Australia, Vanuatu, Septembe Australia: Central Queensland University.

[4] Estes, C., Biggs, S., \& Phillipson, C. (2003). Social theory, social p ricy and age Open University Press: Maidenhead.

[5] Lather, P. (2004). Scientific research in education: a critical crspect Britis Educational Research Journal, 30(6), 759-772.

[6] Marginson, S., \& Sawir, E. (2005). Interrogating glob Jows igher education. Globalization, Societies and Education, 3(3), 281-209.

[7] Mythen, G., \& Walklate, S. (2006). Beyond the isk Society.McGraw Hill: Maidenhead.

[8] Powell, J. L. (2006). Social theory and aging. Rd nan and Ittlefield: Lanham. Powell, J. L. (2011). Aging, theory and globalization. Nova C. New York.

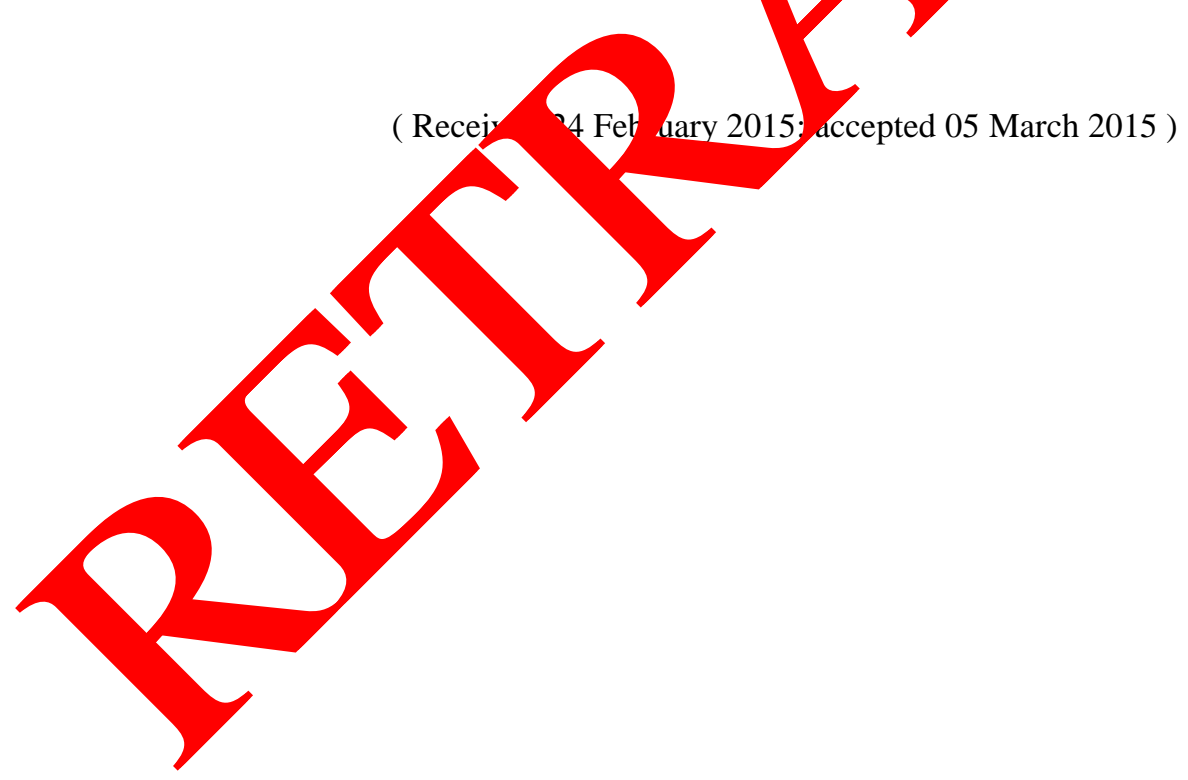

